\title{
O trabalho pedagógico e a alfabetização: práticas e possibilidades
}

\section{The pedagogical work and literacy: practices and possibilities}

https://doi.org/10.34112/2317-0972a2016v34n68p123-135

Mariana Luzia CorrêA Thesing ${ }^{1}$

RESUMO: O processo de alfabetização inicial, em atividades contextualizadas, favorece a formação de leitores e escritores. Este texto, a partir de uma pesquisa bibliográfica (Marconi \& Lakatos, 2003), discute a importância de atividades contextualizadas no processo de alfabetização na escola, tendo em vista o uso social da leitura e da escrita. Apresenta, no decorrer do texto, algumas proposições a serem realizadas nas classes iniciais escolares, voltadas à aprendizagem da leitura e da escrita.

PALAVRAS-ChAVE: Alfabetização; práticas pedagógicas; leitura.

ABSTRACT: The early literacy process, within contextualized activities, favors the preparation of readers and writers. This text, working from a bibliographical research (Marconi \& Lakatos, 2003), discusses the importance of contextualized practices in the literacy process in school, in view of the social use of reading and writing. Throughout the text, a few propositions are presented for early school classes, focusing on reading and writing learning. KEYWORDS: Literacy; pedagogical practices; reading.

1. Universidade Federal de Santa Maria, Santa Maria, RS, Brasil. 
INTRODUÇão

O processo de alfabetização inicial exige um pensar reflexivo do professor alfabetizador a respeito do seu fazer pedagógico, esse que precisa constituir-se como um trabalho significativo e contextualizado. O planejamento do trabalho pedagógico requer o conhecimento acerca da forma como a criança aprende, da maneira como ela pensa o sistema de escrita e como constrói suas hipóteses a respeito dele. O professor precisa conhecer estratégias que sejam efetivamente desafiadoras aos diferentes níveis da lectoescrita, presentes em uma mesma turma.

Os grupos de alfabetização inicial são compostos por crianças que têm diferentes compreensões a respeito do que é ler e escrever a partir das experiências que vivenciam, dentro e fora da escola. São essas diferenciadas experiências que vão compondo as aprendizagens das crianças, estas que se tornam, ao mesmo tempo, aprendizes e ensinantes, pois são capazes de ensinar uns aos outros o que sabem a respeito do que é ler e escrever. Assim, no contexto da sala de aula não é somente o professor quem ensina, ele se torna um mediador das aprendizagens que se fazem mutuamente entre professor e estudantes, em que todos são ensinantes e aprendentes (FREIRE, 1987).

A perda da especificidade do conceito de alfabetização e a postura do professor diante das diferentes concepções dadas a esse termo influenciam diretamente as práticas alfabetizadoras que são desenvolvidas em sala de aula. As concepções dos professores sobre esse processo estão, dessa forma, intimamente relacionadas ao modo como planejam e organizam as atividades nos anos iniciais do Ensino Fundamental.

A prática alfabetizadora fundada no entendimento de que o outro aprende por meio do exercício repetitivo justifica a prática alfabetizadora a partir dos modelos sintéticos de alfabetização - em que se prioriza a exploração da parte para o todo, ou seja, da unidade menor da língua (letra) para as maiores (sílabas, palavras, frases e textos). Por outro lado, quando se compreende que o sujeito aprende a partir de situações contextualizadas, a partir de atividades que envolvam o cotidiano, a prática alfabetizadora fundamenta-se em métodos analíticos, que apostam em atividades do todo para as partes, ou seja, do texto para as unidades menores da língua. E essa 
prática muito se relaciona com utilização/abordagem dos gêneros textuais ${ }^{2}$ nos processos de alfabetização nos anos iniciais escolares.

Com essas premissas, este texto tem o objetivo de discutir sobre os processos de alfabetização inicial na escola. A partir de uma pesquisa bibliográfica (MARCONI; LAKATOS, 2009), este texto discute sobre práticas de atividades importantes de serem pensadas no decorrer do trabalho pedagógico em classes de alfabetização, considerando a importância de serem realizadas a partir de situações contextualizadas e associadas a projetos de trabalho em que as turmas possam estar envolvidas.

\section{A prática Alfabetizadora: Algumas teorizações}

Diante dos universos plurais que configuram as salas de aula com crianças alfabetizandas, poderíamos nos questionar: de que maneira o trabalho alfabetizador pode tornar-se uma prática que valorize a heterogeneidade de vivências destes estudantes e que considere a relevância das práticas sociais de leitura e da escrita? O trabalho em sala de aula nos Anos Iniciais do Ensino Fundamental tem apostado efetivamente em que concepção de trabalho alfabetizador? Quais são os saberes dos professores acerca do processo de ensino da leitura e da escrita? Estarão estes comprometidos com a ideia de formação de sujeitos leitores e escritores em suas realidades?

Há diversas teorizações sobre o processo de alfabetização que embasam as discussões a respeito de métodos de alfabetização adequados, da "melhor" conceituação dos termos alfabetização e letramento, o que revela a ideia de que o primeiro, como nos aponta Soares (2004), vem sofrendo uma "desinvenção". Para essa autora, o conceito de alfabetização tem passado por uma série de reformulações teóricas que, devido a diferenciadas e talvez equivocadas formas de compreendê-lo, conduzem à perda da especificidade deste conceito nas escolas brasileiras.

De acordo com Picolli (2009b), o leitor, diante de diferentes textos que tratam sobre o conceito de alfabetização, precisa fazer inferências para compreender quais são as concepções dos diferentes autores em relação a esse termo, já que essas não estão explícitas. Para alguns autores, o termo alfabetização se caracterizaria por ser

2. Os gêneros textuais, entendidos neste texto na perspectiva de Bakhtin (2002), são textos com funções comunicativas diversas. São variados e apesar de apresentarem características que os distinguem, podem sofrer alterações no decorrer do tempo. Exemplos de gêneros textuais: carta, diário, texto de jornal, receita, bilhete, canções, histórias etc. 
o processo de aprendizagem das relações grafofônicas enquanto o termo letramento se voltaria ao trabalho alfabetizador, tendo em vista os usos e funções sociais da leitura e da escrita. Os dois conceitos são, desta maneira, considerados simultâneos, interdependentes e indissociáveis, porém com naturezas diferentes que exigem estratégias e formas de planejamento de trabalho diferenciadas (SOARES, 2004).

Segundo Emilia Ferreiro (2003), o uso dos dois termos (alfabetização e letramento) configura-se como desnecessário, tendo em vista que o conceito de alfabetização, para a autora, já pressupõe a aprendizagem da leitura e da escrita como um processo baseado nos usos e funções da língua e não apenas como um trabalho baseado na decodificação/codificação ou a simples aprendizagem das relações grafofônicas. Entretanto, para Soares (2004), são justamente as dificuldades de compreensão acerca dos processos de alfabetização e de letramento e da sobreposição das ideias deste último em relação à importância do primeiro que provocaram os fracassos das práticas de alfabetização desenvolvidas nas escolas brasileiras. Eis então a importância, para essa autora, de que esses termos sejam bem definidos, com suas características e formas de planejamento delineadas para que as práticas alfabetizadoras nas escolas brasileiras sejam propostas mais significativas e bem-sucedidas.

O que se propõe é, em primeiro lugar, a necessidade do reconhecimento da especificidade da alfabetização, entendida como processo de aquisição e apropriação do sistema da escrita, alfabético e ortográfico; em segundo lugar, e como decorrência, a importância de que a alfabetização se desenvolva em um contexto de letramento - entendido este, no que se refere à etapa inicial da aprendizagem da escrita, como participação em eventos variados de leitura e escrita, e o consequente desenvolvimento de habilidades de uso da leitura e escrita nas práticas sociais que envolvem a língua escrita, e de atitudes positivas em relação a essas práticas (...). (SOARES, 2004, p. 16).

Pensando sobre o trabalho alfabetizador, na perspectiva das práticas de "alfabetizar letrando", podemos considerar que este se configura como um processo político. É por meio dele que democratizamos o conhecimento e que formamos sujeitos leitores e escritores que leiam as suas realidades e escrevam novas histórias para suas próprias formas de viver e estar no mundo. Assim, o processo de alfabetização, seja ele compreendido como mera aprendizagem das relações grafofônicas ou como aprendizagem do sistema de escrita considerando suas funções e usos 
sociais, configura-se como um trabalho comprometido com um ideal de sociedade e, por isso, é um ato político, que, por sua vez, pode configurar-se como um processo alienador ou libertador. De acordo com Soares (2004, p. 14),

[...] dissociar alfabetização e letramento é um equívoco porque, no quadro das atuais concepções psicológicas, linguísticas e psicolinguísticas de leitura e escrita, a entrada da criança (e também do adulto analfabeto) no mundo da escrita ocorre simultaneamente por esses dois processos: pela aquisição do sistema convencional de escrita - a alfabetização - e pelo desenvolvimento de habilidades de uso desse sistema em atividades de leitura e escrita, nas práticas sociais que envolvem a língua escrita - o letramento. Não são processos independentes, mas interdependentes e indissociáveis: a alfabetização desenvolve-se no contexto de e por meio de práticas sociais de leitura e escrita, isto é, através de atividades de letramento [...].

Torna-se um processo alienador quando as práticas de alfabetização são desenvolvidas sem a devida problematização, ao contrário do que se pensa como proposta libertadora em que há a aprendizagem da leitura não só de palavras soltas, mas dos contextos sociais em que elas estão imbricadas. Para Freire (1989), no processo de alfabetização é fundamental pensarmos sobre as relações entre o ato educativo e o ato político porque, para o autor, essas ideias estão inter-relacionadas. Ele defende que, nessa relação,

[...] uma das questões fundamentais seja a clareza em torno de a favor de queme do quê, portanto contra quem ou contra o quê, fazemos a educação, e de a favor de quem e do quê, portanto contra quem e contra o quê, desenvolvemos a atividade política. Quanto mais ganhamos esta clareza através da prática, tanto mais percebemos a impossibilidade de separar o inseparável: a educação da política. (FREIRE, 1989, p. 15, grifos do autor).

Tendo em vista o processo de alfabetização compreendido como um ato político, voltado para a formação de leitores e escritores, é necessário pensarmos em práticas de trabalho que sejam coerentes com essa visão, planejando atividades de trabalho que promovam espaços para a reflexão sobre a língua, para a vivência com diferentes tipos de texto, suas formas, usos e funções sociais. Por isso, é preciso que não tenhamos restrições com a atividade de leitura e escrita na escola. E isso exige a abertura de espaços mais contextualizados, criativos e dialógicos na escola. 
Precisamos trabalhar numa perspectiva em que a atividade de leitura e escrita vá além de aprender a ler e a escrever só para aprender a juntar letras e a ler/escrever pequenas palavras (sem encontros consonantais, de preferência) e pequenas frases como "A bola é bonita". É necessário avançarmos nessa forma de entender a atividade leitora e escritora na escola, trabalhando com os estudantes os diferentes objetivos em que essas atividades estão alicerçadas.

Nessa perspectiva, Picolli (2009a) nos alerta que as atividades de leitura e escrita na escola precisam ser planejadas e organizadas e não realizadas sem planejamento prévio para desenvolverem as habilidades da área da linguagem: a oralidade, a escrita e a leitura. Para a autora, "as variadas interações das crianças com diferentes gêneros de material escrito não são dadas ao acaso ou ocorrem de forma espontânea, mas pressupõem um planejamento intencional por parte da professora e sua intervenção pedagógica explícita" (PICOLLI, 2009a, p. 15). Assim, é importante considerar que o planejamento dessas atividades na escola precisa embasar-se na contextualização dessas práticas, promovendo-as num processo de construção de sentido para os estudantes. A escrita de uma carta não deve ser só ensaiada para se aprender a fazer cartas, mas precisa estar relacionada a uma prática com significado, como a escrita de uma carta a um querido professor, no dia em que celebramos o dia de seu aniversário, ou a escrita de uma carta a um colega que não vemos por um tempo e com quem queremos manter contato.

Isso porque, por vezes, pode-se escrever na escola sem um objetivo para além da atividade de escrita, sem que essa prática tenha uma necessidade significativa. A escrita é, muitas vezes, uma atividade para o professor ler, para corrigir erros gramaticais e ortográficos, sem que se tenha traçado uma necessidade, como um uso social, de fazê-la. É importante que as crianças desenvolvam essa habilidade e que criem histórias a seu próprio punho e que as dificuldades ortográficas sejam corrigidas nas atividades textuais propostas na escola, mas o que se defende é que essas atividades sejam propostas de trabalho que tenham sentido para as crianças.

Cagliari (2003, p. 101) reitera essa ideia quando nos diz que "a escola é talvez o único lugar onde se escreve muitas vezes sem motivo”. E é esse o grande motivo dos desafetos que podem ser desenvolvidos pelos estudantes com a atividade de escrita. Sem significado, contexto e propósito, a atividade de escrita na escola serve apenas para ser corrigida, com traços de canetas vermelhas, que não tem função social explícita para aquele que escreve. É preciso defender uma proposta na escola em que os estudantes escrevam não só para serem corrigidos, mas também para 
aprenderem que a escrita é um instrumento de registro, de jogo com as palavras, de criação e de reivindicação social.

E a escola, por ter práticas alicerçadas em um ideal de sociedade mais democrático (pelo menos é o que se espera dela) é um espaço de democratização do conhecimento e de aprendizagem das formas de reivindicar modos de vida mais igualitários. A escola precisa desenvolver espaços, tempos e práticas embasados na busca pela justiça social em que todos, sendo leitores e escritores, possam reivindicar seus direitos a fim de reescreverem suas histórias e transformar suas realidades.

\section{As PRÁticas de leitura Na ESCOLA: Algumas PRoposições}

- Terminou a atividade? Muito bem! Seu caderno está muito bem organizado! Agora, até a hora do recreio, você pode ler os livros do fundo da sala. A menina, feliz por ter terminado as propostas feitas pela professora, e pelo elogio recebido, dirige-se até a caixa de livros, no fundo da sala, depois de guardar seu caderno sob a mesa. Após o manuseio de alguns livros, percebe que os exemplares disponíveis na caixa são os mesmos explorados por ela há alguns dias atrás. Com pouco interesse, pega uma das obras e senta no seu lugar, simulando uma atitude leitora, entre pausas e olhares dispersos, a fim de não contrariar a solicitação feita pela professora.

A breve história que abre este texto é uma situação inventada que possivelmente é encontrada como realidade corriqueira nas salas de aula, não exclusiva dos primeiros anos escolares. É, infelizmente, uma prática comum fazer da atividade leitora um exercício de quem já não tem mais atividades a serem realizadas e, por isso, recebem como privilégio o acesso a uma caixa de livros que geralmente está no fundo da sala, no dito "cantinho da leitura”, para ser explorada quando já não há mais atividades a serem cumpridas.

A caixa de livros refere-se a um conjunto de obras tipo folhetos (livros com pouco texto e/ou empobrecidos de conteúdo literário) que dificilmente é remanejado, reorganizado pelo professor, o que contribui para que aqueles que têm a acesso a ela percam a motivação de encontrar novidades e textos interessantes. A atividade de leitura, nessa situação, se torna uma atividade enfadonha, um castigo para aquele que manuseia esses materiais. Diante de um contexto como esse, poderíamos nos questionar: como formar leitores que gostem de ler e que se encantem com as páginas recheadas de belas histórias e ilustrações quando as atividades de leitura são planejadas de forma secundária nas salas de alfabetização? Definitivamente, essa 
forma de organizar o momento de leitura na escola não é considerada uma boa prática para a formação de leitores. É necessário que ela seja refutada das nossas salas de aula se é que acreditamos numa concepção de aprendizagem da leitura que objetive a formação de leitores.

Nas atividades de leitura na escola devem ser apresentadas propostas em que a leitura seja importante por diversas razões e objetivos: ela pode auxiliar na obtenção de informações, na leitura de quem busca ler para aprender como se faz algo que ainda não sabe, na leitura para avançar em nossos conhecimentos sobre determinados assuntos e, principalmente, a atividade leitora como fruição, para se ter prazer, para ser feliz nessa atividade. Mas, para que esses sentidos da atividade de leitura possam ser compreendidos pelos estudantes, desde a tenra infância, precisamos nos tornar referências leitoras para esses sujeitos que, por vezes e por diferenciadas razões, não têm acesso a essas experiências fora do espaço escolar.

A forma como organizamos essa atividade diz muito sobre a importância que damos a ela. Assim, podemos pensar: a atividade de leitura é feita nos períodos iniciais das aulas? Ou nos momentos finais, se há tempo sobrando? É realizada entre as atividades para aqueles que as terminam antes dos demais estudantes? Quais são as obras que ofereço para esses sujeitos? A seleção das obras e a forma como planejo essa atividade têm quais objetivos?

As atividades de leitura e o trabalho com gêneros textuais na escola são objeto de análise deste texto. Essas práticas, aliadas ao processo alfabetizador desenvolvido nos anos iniciais escolares, estão comprometidas com determinadas formas de compreender o conceito de alfabetização e as práticas de leitura e de escrita. A postura do professor que oferece bons materiais de leitura aos seus alunos e que valoriza essa atividade, explorando-a de diferenciadas formas, está comprometida com um ideal de educação para uma sociedade mais igualitária e democrática, voltada para a socialização do conhecimento e para a formação de sujeitos mais leitores e, por isso, mais críticos em relação à própria vida e à condição sócio-política-econômica em que estão inseridos.

A leitura na escola pode ser realizada de diferenciadas formas: nos inícios de aula pelo professor e pelos estudantes ${ }^{3}$, no pátio da escola, em algum lugar aconchegante,

3. A leitura pelos estudantes pode ser proposta como uma atividade diária para a turma, em que cada estudante tem a responsabilidade de ler um livro ou parte dele para seus colegas - ou para outras turmas da escola, proposição que favorece a aprendizagem da leitura, para os alfabetizandos, e para o aperfeiçoamento dessa habilidade para aqueles que já são mais experientes nessa atividade. 
na biblioteca dentre os inúmeros títulos possíveis de serem explorados, em casa com as famílias ${ }^{4}$, em atividades como "histórias novela" em que partes de histórias podem ser contadas em capítulos, dentre outras formas. Os textos lidos devem abranger uma variedade de gêneros e devem ser lidos pelo prazer de lê-los, e não como pretextos para atividades posteriores. A literatura infantil deve ser trabalhada em nome da imaginação, do prazer de folhear um livro e em prol de formação de leitores que tenham em si a sensibilidade para ler diferentes materiais e se apropriarem deles com criticidade. E o mesmo deve ser entendido em relação aos outros gêneros textuais, que também devem ser trabalhados na escola visando à formação de sujeitos autônomos em relação a esses textos, encontrados no cotidiano. Em relação a isso, Ebert (2007) nos diz que,

[...] nesta perspectiva, o trabalho elaborado e desenvolvido pelo professor pode garantir aos alunos o acesso a uma grande variedade de gêneros textuais, proporcionando a habilidade de lidar com eles no cotidiano. O ideal é que o aluno tenha contato com diversos gêneros de textos ao longo do processo de alfabetização e letramento. Há um extenso "oceano" de possibilidades para serem exploradas em aula: panfletos, receitas, manuais, receitas médicas, bula de remédio, documentos pessoais, anúncios de jornais, charges, quadrinhos, poesias, letra de música, bilhetes, ofícios, gravuras, entrevistas, crônicas, fábulas, embalagens, etc. (EBERT, 2007, p. 11-12).

E ler para os alunos muito tem a ver com a formação de escritores. A quanto mais experiências de leitura, a quanto mais referenciais esses estudantes tiverem acesso, mais ideias podem surgir em suas produções de autoria. Quanto mais os estudantes tiverem experiências com a atividade de escrita e souberem como os textos se organizam, mais capazes se tornarão nessa atividade para compor, de forma autoral, os próprios registros. Por isso, é incoerente solicitar a escrita autoral dos estudantes quando estes têm vivenciado poucas experiências na escola com bons materiais de leitura, que se tornam, pelas vivências cotidianas, referenciais de forma e conteúdo para as composições textuais.

4. A leitura nas casas das famílias pode ser incentivada a partir de um conjunto de materiais escritos como jornais, revistas, gibis, livros de desenhos e de curiosidades que é levado para a casa pelas crianças em dias determinados. Duas crianças a cada dois dias, a partir de um sorteio, têm a oportunidade de levar uma sacola, a sacola literária, com esses materiais para casa. Essa prática é bastante interessante porque envolve e convida as famílias das crianças para realizarem leituras compartilhadas. 
Erroneamente acredita-se que a leitura em sala de aula inicia com a aprendizagem das letras, apresentadas uma a uma, ou todas ao mesmo tempo, suas formas de representação, seus nomes e fonemas associados; que é por meio do reconhecimento de seus fonemas que as crianças descobrem que as letras se relacionam e se tornam sílabas com determinados sons, que não poderiam surgir sem tais junções. Assim, as crianças alfabetizandas vão "juntando os pedacinhos", que são as sílabas, e formando/lendo palavras, que são inicialmente simples, mas com a experiência, são capazes de lerem outras sílabas e palavras mais complexas. Contudo, a atividade de leitura é considerada uma prática que vai muito além dessa decodificação dos sinais gráficos. Envolve a disposição do sujeito em se relacionar com um texto, sendo envolvido por ele. Desse pode tirar informações, descobrir novos conhecimentos, estudar novas formas de solucionar problemas, receber notícias. E o texto, nessa relação de encontro, pode provocar no leitor a alegria, a nostalgia, a tristeza, a reflexão.

As crianças, mesmo sem saberem ler, devem ter acesso a diversos tipos de texto que podem ser trabalhados oralmente e registrados pelo professor, este no papel de escriba, para serem trabalhados na sala de aula. Dessa forma, o trabalho com textos na escola, mesmo em classes em que as crianças ainda não sabem ler, é considerado uma atividade essencial, pois está diretamente relacionado ao uso e aos objetivos sociais da leitura e da escrita. Desse modo, é necessário trabalhar, também na Educação Infantil, com a escrita de músicas, de histórias, de parlendas, trava-línguas, receitas, cartas, notícias, poemas etc. Para Ferreiro (2001, p. 98), as crianças, especialmente as advindas das áreas urbanas, já têm experiências com as funções sociais da leitura e escrita mesmo antes de ingressarem na escola, pois "a escrita faz parte da paisagem urbana, e a vida urbana requer continuamente o uso da leitura. As crianças urbanas de 5 anos geralmente já sabem distinguir entre escrever e desenhar; expostas ao complexo conjunto de representações gráficas presentes no seu meio $[. .$.$] ".$

Mesmo sem saberem ler, esses estudantes aprendem a forma de organização dos textos e quais são suas funções sociais. Além de aprender sobre a organização das diferentes tipologias textuais e de seus sentidos e funções sociais, podem avançar na compreensão do que é ler e escrever, avançando na associação de grafemas e fonemas, tendo em vista o trabalho sistemático necessário para essa aprendizagem. 


\section{CONSIDERAÇões Finais}

A discussão sobre as práticas de alfabetização e de leitura e escrita na escola fundamenta-se na pertinência das suas relações com os pressupostos epistemológicos que dão base para essas práticas. Compreende-se que é na contextualização e na significância dessas atividades para a vida social que o processo de alfabetização necessita estar fundamentado. É entendido que a compreensão do professor sobre o processo de aprendizagem da leitura e da escrita pelos sujeitos influencia diretamente seu planejamento de trabalho nos processos de alfabetização.

Há distintas teorizações que se voltam a descrever as metodologias para ensinar a ler e a escrever. Todas estão embasadas, sem neutralidade, em formas diferenciadas de entender o que é aprendizagem, o que é ensino, o que é leitura e escrita e seus respectivos significados sociais. Um professor embasado em referenciais da tendência tradicional de educação, que entende o processo educacional de determinada maneira irá construir suas práticas em sala de aula diferentemente de um professor embasado em referenciais mais progressistas e libertadores. Desse modo, as ideias que norteiam as práticas de alfabetização nos anos iniciais escolares também se diferenciam nesse viés.

Professores que compreendem a aprendizagem da leitura e da escrita como a decodificação/codificação de sinais gráficos terão práticas diferenciadas daqueles que compreendem os processos de aprender a ler e a escrever tendo em vista os usos e funções sociais dessas habilidades na vida cotidiana. Pelo menos, espera-se que estes últimos organizem suas práticas tendo em vista o entendimento de que a formação de leitores e escritores exige um trabalho coerente com essa forma de compreender o processo de ensino da leitura e da escrita: embasado em atividades que tenham significado, contexto e de acordo com suas funções sociais.

A alfabetização sem o trabalho com textos, tendo em vista suas funções sociais, é uma prática que se desenvolve sem significado, empobrecida e descontextualizada. São práticas que se reduzem à aprendizagem do bê-á-bá sem sentido, sem função social, sem objetivo. Nessa perspectiva de trabalho, aprende-se a ler e a escrever para codificar e decodificar letras, palavras e frases, desvinculada da aprendizagem dessas habilidades para o uso na vida cotidiana, em sociedade.

De forma criativa e inovadora, é necessário que se organizem mais tempos e espaços escolares em que se promova a compreensão da importância da língua para a comunicação/interação entre os sujeitos em determinados meios sociais, a partir 
do trabalho com textos de forma contextualizada, com suas funções sociais. Isso para que a formação dos estudantes nas escolas se traduza em processos formativos comprometidos com a formação de novos autores e atores, criadores de uma nova história a ser (re)escrita coletivamente em novos cenários e contextos.

\section{REFERÊNCIAS}

BAKHTIN, Mikhail. Estética da criação verbal. Tradução Paulo Bezerra. São Paulo: Martins Fontes, 2002.

CAGLIARI, Luiz Carlos. Alfabetização \& Lingüística. São Paulo: Editora Scipione, 2003.

EBERT, Síntia Lúcia Faé. A relação letramento e gêneros textuais na alfabetização de jovens e adultos. Cadernos FAPA, Porto Alegre, Número Especial VI Fórum FAPA, p. 07-13, 2007. Disponível em: <http://www.fapa.com.br/cadernosfapa/artigos/edicaoSPforumo7/artigo2.pdf>. Acesso em: 20 jun. 2013.

FERREIRO, Emilia. Reflexões sobre alfabetização. Tradução Horácio Gonzales et al. 24. ed. São Paulo: Cortez, 2001.

. Alfabetização e Cultura Escrita. Revista Nova Escola. São Paulo, n. 162, maio. 2003, p. 30.

Disponível em: <http://www.cereja.org.br/arquivos_upload/emiliaferreiro_novaescola162. pdf $>$. Acesso em: 16 jun. 2013.

FREIRE, Paulo. Pedagogia do Oprimido. 17. ed. Rio de Janeiro: Paz e Terra, 1987.

. A importância do ato de ler: em três artigos que se completam. 23. ed. São Paulo: Autores Associados: Cortez, 1989.

MARCONI, Marina de Andrade; LAKATOS, Eva Maria. Fundamentos de Metodologia Cientifica. 5. ed. São Paulo: Editora Atlas, 2003.

PICOLLI, Luciana. Práticas escolares de letramento e gêneros textuais: interlocuções e implicações pedagógicas. In: IV SIMPÓSIO INTERNACIONAL DE ESTUDOS DE GÊNEROS TEXTUAIS, 4., 2009, Caxias do Sul. Anais... Caxias do Sul: UCS, 2009a. p.01-17. Disponível em: <http://www.ucs.br/ucs/tplSiget/extensao/agenda/eventos/vsiget/portugues/anais/textos_ autor/arquivos/praticas_escolares_de_letramento_e_generos_textuais_interlocucoes_e_ implicacoes_pedagogicas.pdf $>$. Acesso em: 12 jun. 2013.

.Prática pedagógica nos processos de alfabetização e letramento: análises a partir dos campos da sociologia e da linguagem. Porto Alegre, 2009. 238 f. Tese (Doutorado em Educação). Programa de Pós-Graduação em Educação, Faculdade de Educação, Universidade Federal do Rio Grande do Sul, Porto Alegre, 2009b.

SOARES, Magda. Letramento e alfabetização: as muitas facetas. Revista Brasileira de Educação, n. 25, p. 05-17, jan./fev./mar./abr. 2004. Disponível em: <http://www.scielo.br/pdf/rbedu/n25/ n25ao1.pdf>. Acesso em: 13 jan. 2016. 
SOBRE A AUTORA

Mariana Luzia Corrêa Thesing é graduada em Pedagogia (Universidade Federal de Santa Maria), com Especialização em Atendimento Educacional Especializado (Universidade Estadual de Maringá) e Especialização em Gestão do Cuidado: para uma escola que protege (Universidade Federal de Santa Catarina). Tem Mestrado em Educação (Pontifícia Universidade Católica do Rio Grande do Sul) e é doutoranda do Programa de Pós-Graduação em Educação da Universidade Federal de Santa Maria (UFSM), na Linha de Pesquisa de Educação Especial. Tem experiência como professora da Educação Infantil e Anos Iniciais do Ensino Fundamental e do ensino de disciplinas pedagógicas e supervisão de estágio em curso de formação de professores.

E-mail: marluzcor@gmail.com

Recebido em 20 de julho de 2016 e aprovado em 15 de dezembro de 2016. 